\title{
ARTICLE
}

Received 29 May 2015 | Accepted 26 Aug 2015 | Published 7 Oct 2015

DOI: $10.1038 /$ ncomms 9488

OPEN

\section{Energetics of proton release on the first oxidation step in the water-oxidizing enzyme}

Keisuke Saito1,2,3, A. William Rutherford ${ }^{4}$ \& Hiroshi Ishikita ${ }^{1,2}$

In photosystem II (PSII), the $\mathrm{Mn}_{4} \mathrm{CaO}_{5}$ cluster catalyses the water splitting reaction. The crystal structure of PSII shows the presence of a hydrogen-bonded water molecule directly linked to $\mathrm{O} 4$. Here we show the detailed properties of the $\mathrm{H}$-bonds associated with the $\mathrm{Mn}_{4} \mathrm{CaO}_{5}$ cluster using a quantum mechanical/molecular mechanical approach. When $\mathrm{O} 4$ is taken as a $\mu$-hydroxo bridge acting as a hydrogen-bond donor to water539 (W539), the $\mathrm{S}_{0}$ redox state best describes the unusually short $\mathrm{O}_{4}-\mathrm{O}_{\mathrm{W} 539}$ distance $(2.5 \AA)$ seen in the crystal structure. We find that in $\mathrm{S}_{1}, \mathrm{O} 4$ easily releases the proton into a chain of eight strongly hydrogen-bonded water molecules. The corresponding hydrogen-bond network is absent for $\mathrm{O} 5$ in $\mathrm{S}_{1}$. The present study suggests that the O4-water chain could facilitate the initial deprotonation event in PSII. This unexpected insight is likely to be of real relevance to mechanistic models for water oxidation.

\footnotetext{
${ }^{1}$ Research Center for Advanced Science and Technology, The University of Tokyo, 4-6-1 Komaba, Meguro-ku, Tokyo 153-8904, Japan. ${ }^{2}$ Department of Applied Chemistry, The University of Tokyo, 7-3-1 Hongo, Bunkyo-ku, Tokyo 113-8654, Japan. ${ }^{3}$ Japan Science and Technology Agency (JST), PRESTO, 4-1-8 Honcho Kawaguchi, Saitama 332-0012, Japan. ${ }^{4}$ Department of Life Sciences, Sir Ernst Chain Building, Imperial College London, London SW7 2AZ, UK. Correspondence and requests for materials should be addressed to H.I. (e-mail: hiro@appchem.t.u-tokyo.ac.jp).
} 
T he core of the photosystem II (PSII) reaction center is composed of D1/D2, a heterodimer of protein subunits that contains the cofactors involved in photochemical charge separation, quinone reduction and water oxidation. In PSII, the $\mathrm{Mn}_{4} \mathrm{CaO}_{5}$ cluster catalyses the water splitting reaction: $2 \mathrm{H}_{2} \mathrm{O} \rightarrow \mathrm{O}_{2}+4 \mathrm{H}^{+}+4 \mathrm{e}^{-}$(reviewed in refs 1,2 ). The release of protons has been observed in response to changes in the oxidation state (the $S_{n}$ state, where the subscript represents the number of oxidation steps accumulated) of the oxygen-evolving complex and occurs with a typical stoichiometry of 1:0:1:2 for the $S_{0} \rightarrow S_{1} \rightarrow S_{2} \rightarrow S_{3} \rightarrow S_{0}$ transitions, respectively (for example, refs 3,4$)$. Although the relevant pathway for proton transfer (PT) in each S-state transition is not yet clear, PT may proceed via different pathways in the PSII protein, depending on the S-state transition $^{5-7}$. Candidates for the relevant PT pathways have been reviewed recently $y^{7-12}$ and site-directed mutagenesis studies are testing the various possibilities ${ }^{13}$.

The majority view in the current literature is that the best resolved X-ray crystal structure (1.9 $\AA$ ) of the $\mathrm{Mn}_{4} \mathrm{CaO}_{5}$ cluster ${ }^{14}$ represents an over-reduced form due to its reduction by the X-ray beam (for example, ref. 1 but see also for example, ref. 15 for an alternative explanation). This was suggested to explain the elongation of $\mathrm{Mn}-\mathrm{Mn}$ and $\mathrm{Mn}-\mathrm{O}$ distances compared with those obtained from extended X-ray absorption fine structure (EXAFS; for example, refs 16-21). Detailed oxidation states of the 1.9- $\AA$ crystal structure are discussed in recent theoretical studies (see ref. 22 and references therein). Electron spin echo envelope modulation (ESSEM) and electron-nuclear double resonance (ENDOR) studies have suggested that all of the $\mu$-oxo bridges of the $\mathrm{Mn}_{4} \mathrm{CaO}_{5}$ cluster are deprotonated in the $\mathrm{S}_{2}$ state, and that the water molecules, W1 and $\mathrm{W} 2$, bound to $\mathrm{Mn} 4$ are $\mathrm{H}_{2} \mathrm{O}$ or $\mathrm{OH}^{-}$(refs 23,24). Because proton release is not observed in the $\mathrm{S}_{1}-\mathrm{S}_{2}$ transition, the ESEEM and ENDOR data thus imply that the $\mu$-oxo bridges of the $\mathrm{Mn}_{4} \mathrm{CaO}_{5}$ cluster are already deprotonated in $\mathrm{S}_{1}$ (refs 16,19-21,25). The 1.9- $\AA$ structure revealed that two water molecules, W1 and W2, were ligands to the $\mathrm{Mn} 4$ atom of the $\mathrm{Mn}_{4} \mathrm{CaO}_{5}$ cluster, and two waters, W3 and W4, were ligands to the Ca atom ${ }^{14}$. W3 has been proposed as a candidate deprotonation site because it is one of the closest water molecules to the redox active Tyr $\mathrm{Z}^{14}$ and because the W3-Sr bond in the $\mathrm{Mn}_{4} \mathrm{SrO}_{5}$ cluster was specifically longer compared to that in the $\mathrm{Mn}_{4} \mathrm{CaO}_{5}$ cluster ${ }^{26}$. All of these bound water molecules are candidates not only as potential substrates for water oxidation (for example, refs 14,27-32) but also as ionizable groups that could undergo deprotonation during the enzyme cycle in which positive charge equivalents are accumulated ${ }^{21}$.

In recent experimental (for example, ref. 33) and theoretical studies (for example, refs 34,35 ) it has been proposed that the proton released on the $S_{0}-S_{1}$ transition involves hydroxyl form of $\mathrm{O} 5$, an oxygen atom that occupies one of the corners of the cubane, linking the $\mathrm{Ca}, \mathrm{Mn} 3$ and $\mathrm{Mn} 1$ and connecting the cubane to $\mathrm{Mn} 4$. Recently however, in the radiation-damage-free PSII crystal structure obtained using the X-ray free electron laser, which is assumed to be in the $\mathrm{S}_{1}$ state, Suga et al. ${ }^{36}$ proposed that $\mathrm{O} 5$ is a hydroxide ion in $S_{1}$. This was based on the observation of significantly long distances between $\mathrm{O} 5$ and the adjacent $\mathrm{Mn}$ ions ${ }^{36}$. This would be conflict with the already deprotonated $\mu$-oxo bridges in $S_{1}$ suggested from the ESEEM and ENDOR data ${ }^{19-21}$. Recent report comparing published quantum mechanical/molecular mechanical (QM/MM) data and EXAFS data ${ }^{37}$ with the free electron laser structure ${ }^{36}$ suggested that the crystals used for this study could contain significant amount of the reduced $\mathrm{S}_{0}$ state ${ }^{38}$. Notably, the activation energy is specifically low in the $S_{0}-S_{1}$ transition, and can be rationalized as a rate-limiting electron transfer followed by a deprotonation step ${ }^{21}$.

The 1.9- $\AA$ structure shows the presence of a chain of strongly H-bonded eight-water molecules (O4-water chain) directly linked to $\mathrm{O} 4$ (linking $\mathrm{Mn} 4$ and $\mathrm{Mn} 3$ in the $\mathrm{Mn}_{3} \mathrm{CaO}_{4}$-cubane), whereas $\mathrm{O} 5$ has no direct-H-bond partner ${ }^{14}$. As far as we are aware, none of the QM/MM studies have considered the O4-water chain explicitly. In the 1.9-A structure, the water molecule W539 (Bfactor: monomer $\mathrm{A}=23.9$, monomer $\mathrm{B}=25.2$ ) is situated near the $\mathrm{O} 4$ atom of the $\mathrm{Mn}_{4} \mathrm{CaO}_{5}$ cluster ${ }^{14}$. Remarkably, the H-bond between $\mathrm{O} 4$ and $\mathrm{W} 539\left(\mathrm{O} 4-\mathrm{O}_{\mathrm{W} 539}\right)$ is unusually short $(\sim 2.5 \AA)$ in comparison with typical O-O distances of $\sim 2.8 \AA$ for standard (asymmetric) $\mathrm{H}$-bonds in $\mathrm{H}_{2} \mathrm{O}$ (refs 39,40), even if we consider the uncertainty of $\sim 0.16 \AA$ in the measured distances within the 1.9- $\AA$ structure ${ }^{14}$. Notably, 'single-well H-bonds' are very short and typically have $\mathrm{O}-\mathrm{O}$ distances of $2.4-2.5 \AA$ (refs 41,42 ). This results in an essentially barrier-less potential between the H-bond donor and acceptor moieties. The appearance of single-well $\mathrm{H}$-bonds in protein environments is often associated with PT events ${ }^{43-45}$.

Here we look for short $\mathrm{H}$-bonds in the environment of the $\mathrm{Mn}_{4} \mathrm{CaO}_{5}$ complex and investigate their significance in energy terms by adopting a large-scale $\mathrm{QM} / \mathrm{MM}$ approach based on the crystal structure analysed at $1.9 \AA$ resolution ${ }^{14}$.

\section{Results}

A short $\mathrm{H}$-bond between $\mathrm{O} 4$ and W539. The $\mathrm{O}_{4}-\mathrm{O}_{\mathrm{W} 539}$ bond is unusually short in the original $1.9-\AA$ structure $(2.50 \AA \text {, Fig. } 1)^{14}$. When an $\mathrm{H}$-bond is assumed for the $\mathrm{O}_{-}-\mathrm{O}_{\mathrm{W} 539}$ bond, two $\mathrm{H}$-bond patterns are possible. Case 1: the $\mathrm{H}$ atom is from $\mathrm{O} 4$, an $\mathrm{OH}^{-}$moiety, so that the bond can be written $\mathrm{O} 4-\mathrm{H} \ldots \mathrm{O}_{\mathrm{W} 539}$. Case 2: the $\mathrm{H}$ atom is from the water, W539, so that $\mathrm{O} 4 \mathrm{is}^{2-}$ and the bond can be written as $\mathrm{O} 4 \ldots \mathrm{H}-\mathrm{O}_{\mathrm{W} 539}$ (Supplementary Fig. 1). Using these two cases, we investigated whether formation of the short H-bond between O4 and W539 is energetically possible in the $S_{-1}$ to $S_{1}$ states of the high oxidation state model. In the low oxidation state model these $\mathrm{Mn}$ valence states correspond to the $S_{1}-S_{3}$ states $^{15}$ and this option was also investigated (Table 1), however in the present study, if not otherwise specified, the S-states given refer to the high oxidation state model. For discussions of the Mn oxidation state of the low oxidation state model ${ }^{46}$, see Supplementary Discussion.

Case 1. O4 is an $\mathrm{H}$-bond donor $\left(\mathrm{O} 4=\mathrm{OH}^{-}\right)$to W539 ("pre$P T " H$-bond pattern $)$. In $\mathrm{S}_{0}((\mathrm{Mn} 1, \mathrm{Mn} 2, \mathrm{Mn} 3, \mathrm{Mn} 4)=(\mathrm{III}, \mathrm{IV}$, III, III)), QM/MM calculations reproduced a short H-bond distance of $\sim 2.5 \AA$ ( $2.55 \AA$, Table 1$)$ for $\mathrm{O}_{4}-\mathrm{O}_{\mathrm{W} 539}$ only when $\mathrm{O} 4$ was $\mathrm{OH}^{-}$and donated an $\mathrm{H}$-bond to W539 ('pre-PT' pattern in Fig. 2; Table 1). In $\mathrm{S}_{1}$, the energy profile of the $\mathrm{O}_{-}-\mathrm{O}_{\mathrm{W} 539}$ bond (Fig. 3a) resembles an energetically unstable single-well H-bond (Supplementary Fig. 2). These results indicate that matching of the $\mathrm{p} K_{\mathrm{a}}$ values of the donor (that is, O4, Supplementary Fig. 1) and acceptor (that is, W539) moieties occurs in $S_{1}$. Due to the presence of the single-well H-bond (for example, ref. 47), the 'pre-PT' H-bond pattern (Fig. 2) was energetically unstable in $S_{1}$ (discussed later). Note that a single-well $\mathrm{H}$-bond has its energy minimum only at the O-O distance of $\sim 2.5 \AA$ (for example, not 2.6 or $2.7 \AA$ (ref. 43)).

Case 2. W539 is an $\mathrm{H}$ bond donor to $\mathrm{O} 4\left(\mathrm{O} 4=\mathrm{O}^{2-}\right.$ ) ("post-PT" H-bond pattern). In the over-reduced state, $S_{-1}, Q M / M M$ calculations also reproduced the short $\mathrm{H}$-bond distance of $\sim 2.5 \AA$ for O4-O $\mathrm{W}_{\mathrm{W} 39}$ (Table 1) but only when $\mathrm{O} 4$ was $\mathrm{O}^{2-}$ and when it accepted an H-bond from W539 ('post-PT' pattern in Fig. 2).

PT from $\mathrm{OH}^{-}$at $\mathrm{O} 4$ along the O4-water chain. In the QM/MM calculations, $\mathrm{OH}^{-}$at $\mathrm{O} 4$ was stable as an $\mathrm{H}$-bond donor to W539 in $\mathrm{S}_{0}$ and lower $\mathrm{S}$ states (Fig. 3). However, in the $\mathrm{S}_{1}$ state, $\mathrm{OH}^{-}$at O4 was energetically unstable due to formation of the single-well $\mathrm{H}$-bond, leading to the release of a proton from $\mathrm{OH}^{-}$at $\mathrm{O} 4$ and the formation of $\mathrm{O}^{2-}$ at $\mathrm{O} 4$. Remarkably, the released proton was 

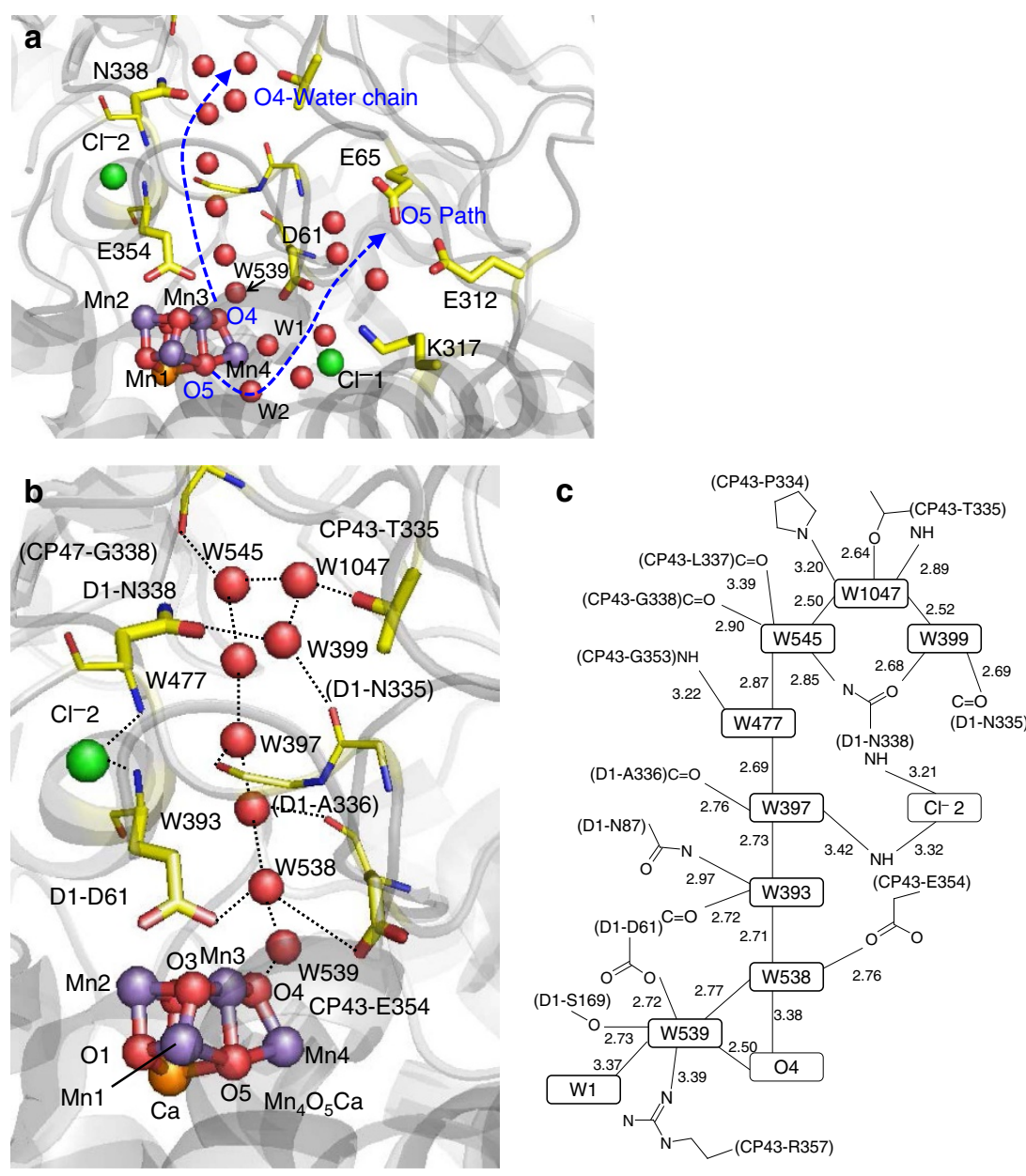

Figure 1 | $\mathbf{H}$-bond networks near the $\mathbf{M n}_{\mathbf{4}} \mathbf{C a O}_{\mathbf{5}}$ cluster. (a) Overview. The O4-water chain is the $\mathrm{H}$-bond network directly linked to the $\mathrm{Mn}_{4} \mathrm{CaO}{ }_{5}$ cluster $\left(\mathrm{O} 4-\mathrm{O}_{\mathrm{W} 539}=2.50 \AA\right)$. The $\mathrm{O} 5$ path is not directly $\mathrm{H}$-bonded to the $\mathrm{Mn}_{4} \mathrm{CaO}_{5}$ cluster $\left(\mathrm{O} 5-\mathrm{O}_{\mathrm{W} 2}=3.08 \AA\right)$. (b) The water chain linked to $\mathrm{O} 4$ of the $\mathrm{Mn}_{4} \mathrm{CaO}_{5}$ cluster in the 1.9- $\AA$ structure ${ }^{14}$. Water molecules (red), $\mathrm{Cl}^{-} 2$ (green) and $\mathrm{Mn}_{4} \mathrm{CaO}_{5}$ (purple, orange, and red for $\mathrm{Mn}, \mathrm{Ca}$, and $\mathrm{O}$ atoms, respectively) are depicted as balls. H-bonds or ionic interactions are represented by dotted lines. (c) H-bond distances in the water chain $(\AA)$.

Table 1 | H-bond geometries (in Ångstroms) of the 04 site.

\begin{tabular}{|c|c|c|c|c|c|c|c|}
\hline \multirow{2}{*}{ High (low) ${ }^{\star}$} & & \multicolumn{3}{|c|}{ pre-PT $\left(04=\mathrm{OH}^{-}\right)$} & \multicolumn{3}{|c|}{ post-PT $\left(04=0^{2-}\right)$} \\
\hline & & $S_{1}\left(S_{3}\right)$ & $S_{0}\left(S_{2}\right)$ & $S_{-1}\left(S_{1}\right)$ & $S_{1}\left(S_{3}\right)$ & $S_{0}\left(S_{2}\right)$ & $S_{-1}\left(S_{1}\right)$ \\
\hline O4-539 & 2.50 & 2.45 & 2.55 & 2.64 & 2.58 & 2.57 & 2.49 \\
\hline $538-393$ & 2.71 & 2.60 & 2.64 & 2.66 & 2.70 & 2.68 & 2.65 \\
\hline 393-397 & 2.73 & 2.62 & 2.64 & 2.67 & 2.75 & 2.72 & 2.71 \\
\hline $397-477$ & 2.69 & 2.83 & 2.83 & 2.87 & 2.68 & 2.66 & 2.64 \\
\hline $477-545^{\dagger}$ & 2.87 & 2.72 & 2.71 & 2.71 & 2.71 & 2.70 & 2.69 \\
\hline RMSD: $\mathrm{Mn}_{4} \mathrm{Ca}$ & & 0.11 & 0.20 & 0.18 & 0.16 & 0.24 & 0.16 \\
\hline RMSD: $\mathrm{Mn}_{4} \mathrm{CaO}_{5}$ & & 0.27 & 0.31 & 0.30 & 0.30 & 0.30 & 0.30 \\
\hline
\end{tabular}

RMSD, root-mean-square deviation.

*High oxidation state model in normal script (low oxidation state model in italics and parenthesis ${ }^{15}$ ).

†The large deviation of the W477-W545 length from the 1.9- $\AA$ structure ${ }^{14}$ originates from the poorer density specifically for W477 in the crystal (Supplementary Fig. 8). In the O4-water chain, W477 is the only water molecule that does not donate an $\mathrm{H}$-bond to a backbone $\mathrm{C}=\mathrm{O}$ but accepts an $\mathrm{H}$-bond from the backbone NH of CP43-G353 (Fig. 1) and this seems to be associated with the greater disorder.

$\mathrm{O} 5=\mathrm{O}^{2-} ; \mathrm{O} 4=\mathrm{OH}^{-}$in pre-PT and $\mathrm{O}^{2-}$ in post-PT. RMSD of the optimized heavy atoms with respect to those of the 1.9- $\AA$ structure. Short $\mathrm{H}$-bond distances $(<\sim 2.5 \AA)$ are in bold.

stabilized at $\mathrm{W} 1047$ in the form of $\mathrm{H}_{3} \mathrm{O}^{+}$, which is $13.5 \AA$ away from O4 (Fig. 1). Overall, the pre-PT pattern (Fig. 2) in the initial state completely transformed into the post-PT pattern (Fig. 2) as a result of PT.
The short $\mathrm{O}_{4}-\mathrm{O}_{\mathrm{W} 539}$ in the pre-PT conformation lengthened to $\sim 2.58 \AA$ in the post-PT pattern in $S_{0}$ or $S_{1}$ (Table 1 ) from $2.50 \AA$ in the $1.9-\AA$ structure. This longer $\mathrm{H}$-bond in $\mathrm{S}_{0}$ or $\mathrm{S}_{1}$ is consistent with $\mathrm{O}_{4}-\mathrm{O}_{\mathrm{W} 539}$ distances of $2.59 \AA$ in both PSII 

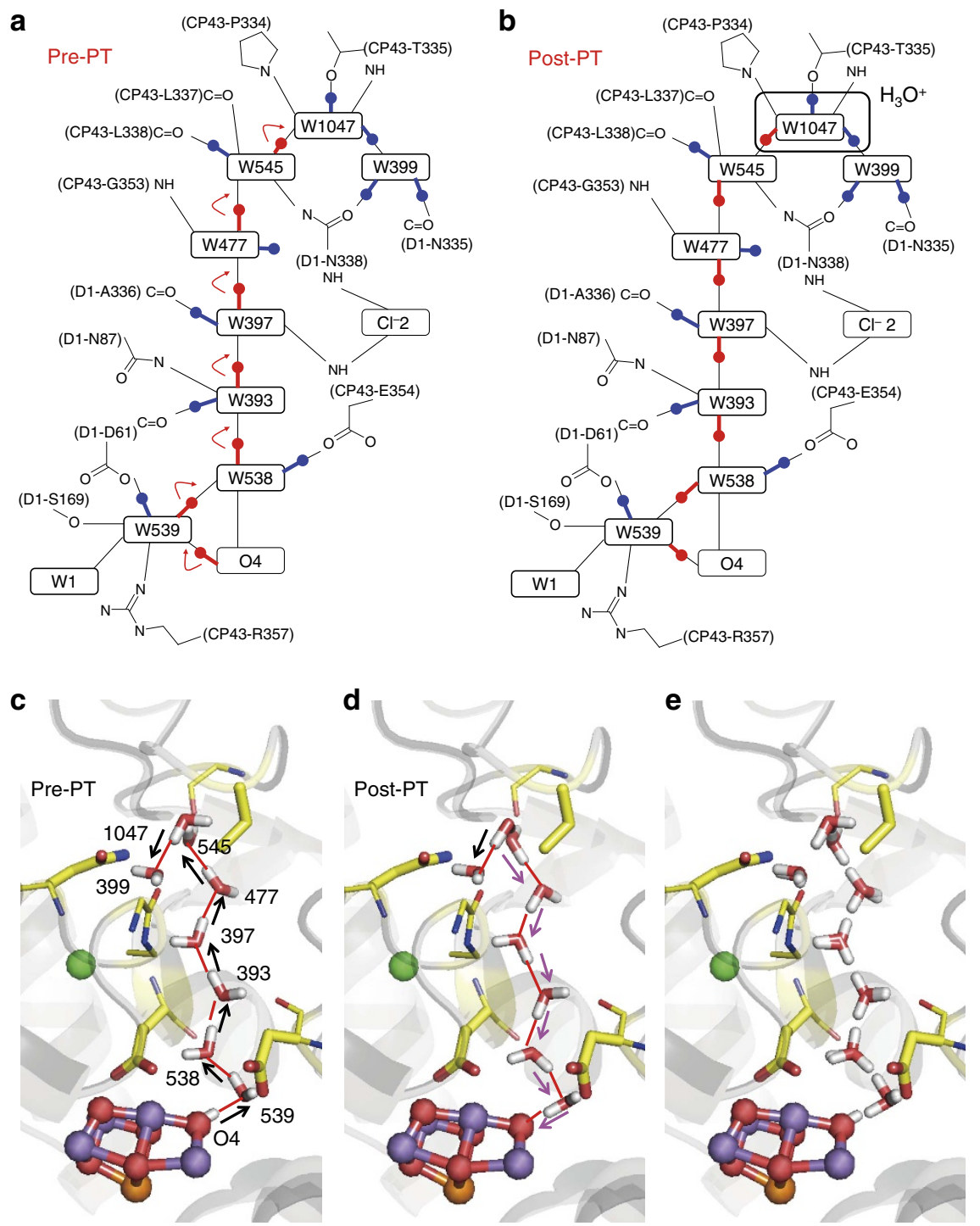

Figure 2 | H-bond pattern change of the entire water chain induced by a release of a proton from 04. (a,b) The two H-bond patterns (pre- and post-PT) possess the same net charge and the same number of $\mathrm{H}$ atoms. Altered and unaltered $\mathrm{H}$-bonds are indicated by red and blue lines and balls, respectively. (c) QM/MM optimized geometries in the pre-PT, (d) post-PT and (e) both conformations. Initial donor-to-acceptor orientations are indicated by black arrows, whereas altered donor-to-acceptor orientations in the post-PT conformation are indicated by magenta arrows.

monomers in the recent radiation-damage-free PSII crystal structure obtained using the X-ray free electron laser (Supplementary Table 1$)^{36}$. These results seem to correspond to a situation in which the free electron laser structure ${ }^{36}$ has the $S_{0}$ or $\mathrm{S}_{1}$ state in which the $\mathrm{O} 4$ is deprotonated, while in the earlier conventional X-ray diffraction structure $(1.9-\AA \text { structure })^{14}$ the $\mathrm{Mn}_{4} \mathrm{CaO}_{4}$ is in a more reduced state and exhibiting a single-well $\mathrm{H}$-bond between $\mathrm{O} 4$ and $\mathrm{O}_{\mathrm{W} 539}$.

In the 1.9- $\AA$ structure, W1047 has unusually short H-bonds, $\mathrm{O}_{\mathrm{W} 1047}-\mathrm{O}_{\mathrm{W} 545} \quad(2.50 \AA)$ and $\mathrm{O}_{\mathrm{W} 1047}-\mathrm{O}_{\mathrm{W} 399} \quad(2.52 \AA)^{14}$. Intriguingly, the short $\mathrm{O}-\mathrm{O}$ distances were reproduced only when we assumed the post-PT H-bond pattern of the O4-water chain (2.46-2.54 $\AA$, Table 1 and Supplementary Table 2). In general, typical $\mathrm{H}_{2} \mathrm{O} \ldots \mathrm{H}_{3} \mathrm{O}^{+}$(that is, the Zundel cation) has an unusually short $\mathrm{O}-\mathrm{O}$ distance of $\sim 2.4 \AA$ (refs 39,40 ). Therefore, the short H-bond distances of W1047 in the 1.9- $\AA$ structure imply that W1047 is capable of forming $\mathrm{H}_{3} \mathrm{O}^{+}$. Remarkably, the $\mathrm{X}$-ray free electron laser structure ${ }^{36}$ also has unusually short H-bonds at the corresponding positions (Supplementary Table 1), a further indication that the X-ray free electron laser structure represents the post-PT state. The presence of these single-well $\mathrm{H}$-bonds indicates that local movement of a proton within the O4- $\mathrm{O}_{\mathrm{W} 539}$ bond of $\sim 2.5 \AA$ results in a sequential downhill PT from O4 to W1047 over a distance of $13.5 \AA$ (Fig. 2 and Supplementary Fig. 3).

A working model. The results indicate that PT occurs through the O4-water chain and thence towards the lumenal bulk surface via PsbU (Supplementary Discussion). This PT reaction is specifically associated with the $S_{0}-S_{1}$ transition. This is supported by the following arguments.

The O4-water chain is the H-bond network in the 1.9- $\AA$ structure $^{14}$ that is directly linked with the $\mathrm{O}$ atoms of the $\mathrm{Mn}_{4} \mathrm{CaO}_{5}$ cluster (via the $\mathrm{O} 4-\mathrm{O}_{\mathrm{W} 539}$ bond). The energy barrier for PT along the $\mathrm{O}_{-}-\mathrm{O}_{\mathrm{W} 539}$ bond is clearly the lowest among all the possible $\mathrm{Mn}_{4} \mathrm{CaO}_{5}$ deprotonation sites in the 1.9- $\AA$ structure $^{14}$. This should contribute to a smaller activation energy for deprotonation, a property consistent with the known characteristics of the $S_{0}-S_{1}$ transition, which includes its rate 

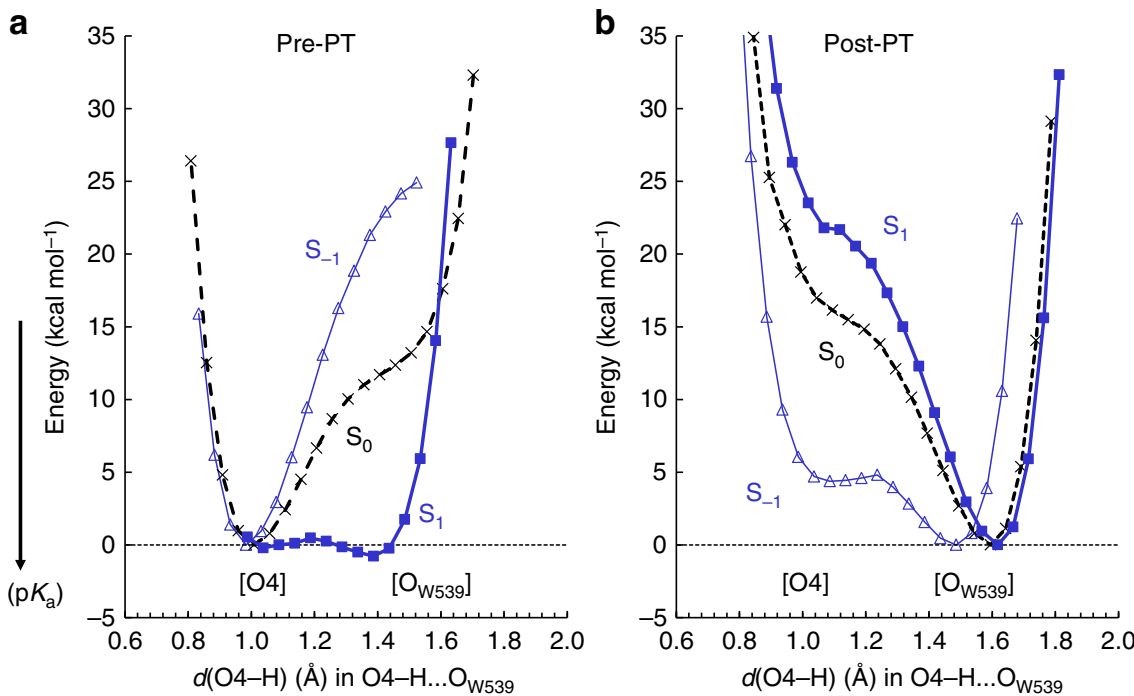

Figure 3 | The energy profiles along the PT coordinate for the $\mathbf{0 4}_{-} \mathbf{O}_{\mathbf{w 5 3 9}}$ bond. (a) pre-PT and (b) post-PT in $\mathrm{S}_{1}$ (blue solid curve), $\mathrm{S}_{0}$ (black dotted curve) and $\mathrm{S}_{-1}$ (blue thin solid curve). For comparison, the energy minimum in the $\mathrm{O} 4$ moiety was set to zero for all $\mathrm{S}$ states.

being insensitive to $\mathrm{H}_{2} \mathrm{O} / \mathrm{D}_{2} \mathrm{O}$ exchange and its activation energy being low compared that of the $S_{2}-S_{3}$ transition $^{21,48,49}$. In the energy profiles of the H-bonds studied here, a proton became energetically more stable as it moved away from $\mathrm{Mn}_{4} \mathrm{CaO}_{5}$, indicating that a downhill PT reaction occurs specifically on the $\mathrm{S}_{0}-\mathrm{S}_{1}$ transition (Fig. 4). The driving force for the PT towards the protein surface in $S_{1}$ is attributed to the increased positive charge on $\mathrm{Mn}_{4} \mathrm{CaO}_{5}$ on the $\mathrm{S}_{0}-\mathrm{S}_{1}$ transition and this conclusion was supported by the observation that lower S-states resulted in the uphill PT reaction (Fig. 4 and Supplementary Fig. 4).

The remarkable linear, eight-water molecular chain acting as Grotthuss-like proton conduit, which is reported here, might be expected to work with very fast kinetics. However, proton release on this step occurs relatively slowly (tens of microsecond ${ }^{21}$ ). This is easily understandable since the electron transfer step occurs before $\mathrm{H}^{+}$release and is thus rate-limiting ${ }^{21}$.

Energetics of proton release from 05. In the present work we also analysed the energy profiles of the PT along the O5 path that proceeds from $\mathrm{O} 5$ to D1-Asp61 via the water molecules, W2, W446 and W442 (Fig. 5). W2 is the only possible proton acceptor from $\mathrm{OH}^{-}$at $\mathrm{O} 5$ when the original geometry of the 1.9- $\AA$ (ref. 14) or X-ray free electron laser $^{36}$ structure is maintained (see below and Supplementary Discussion). When $\mathrm{OH}^{-}$at W2 becomes $\mathrm{H}_{2} \mathrm{O}$ by accepting the proton from $\mathrm{OH}^{-}$at $\mathrm{O} 5$ (Fig. 6b and Supplementary Fig. 5b), W2 cannot release a proton easily to its H-bond acceptor W446 (Fig. 6b,c and Supplementary Fig. 5b,c, see Supplementary Discussion for details), thus causing a significant energy barrier for further PT (Fig. 6). Note that the PT from O5 to W2 is more unlikely when $\mathrm{W} 2=\mathrm{H}_{2} \mathrm{O}$ (Supplementary Fig. 6) due to the even less appropriate $\mathrm{H}$-bond angle for O5...W 2 (Fig. 7).

For a PT, formation of a proton conducting wire (that is, proton donor and acceptor pairs), which is itself an activated process, must occur first ${ }^{50}$. The activation-less 'pre-organized' proton conducting wire possesses well-arranged water groups along the O4-water chain (Fig. 2e) and appears to be achieved by the 'pre-organized protein dipole ${ }^{51}$ ' of PSII. A corresponding feature is absent (for example, a partial H-bond network) in the $\mathrm{O} 5$ path (Fig. 5), suggesting that a sequential downhill PT from $\mathrm{O} 5$ is unlikely. It seems clear that deprotonation of a putative

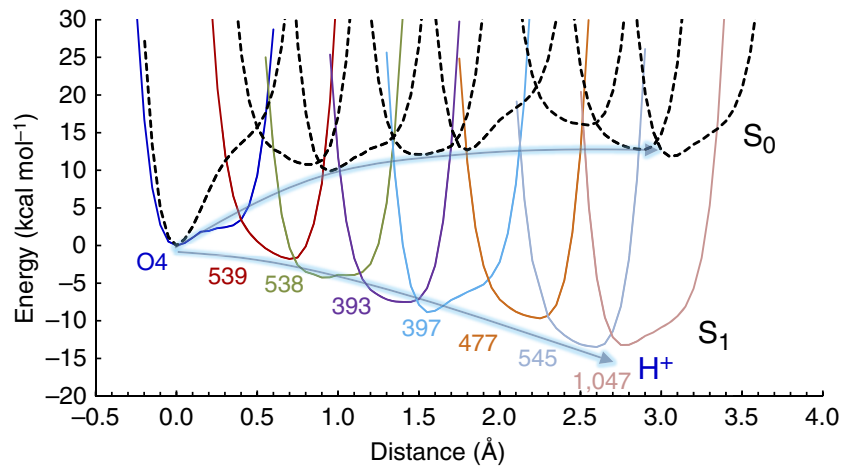

Figure 4 | The energy profiles along the PT coordinate for all of the $\mathrm{H}$-bonds along the 04-water chain in the pre-PT conformation; $\mathbf{S}_{\mathbf{1}}$ (coloured solid curves) and $S_{0}$ (black dotted curves). For comparison, the energy minimum in the $\mathrm{O} 4$ moiety was set to zero for all $\mathrm{S}$ states. For efficient analysis, the small QM region was adopted. In QM/MM calculations the electrostatic interactions, which are calculated from parametrized partial atomic charge, are sometimes intentionally overestimated. The correct treatment of long-range electrostatics in QM/MM calculations is hard to achieve (see for example, ref. 69) and some improvements are in progress (for example, ref. 70). The present results are to be considered qualitatively.

$\mathrm{OH}^{-}$at $\mathrm{O} 5$ is less likely than $\mathrm{OH}^{-}$at $\mathrm{O} 4$. The activation barrier of the $\mathrm{O} 5$ path appears to remain high in $\mathrm{S}_{1}$ (Fig. 6); it might be possible however that this path becomes active in proton conduction in higher $\mathrm{S}$ states.

Alternative $\mathrm{O} 5$ deprotonation models. Although some studies have suggested or assumed that $\mathrm{O} 5\left(=\mathrm{OH}^{-}\right)$deprotonation occurs on the $\mathrm{S}_{0}-\mathrm{S}_{1}$ transition $^{33-35}$, it should also be noted that $\mathrm{O} 5$ has no direct-H-bond partner in the original geometry of the 1.9-A structure ${ }^{14}$ (Fig. 7) and in the free electron laser structure ${ }^{36}$. Recent QM/MM studies by Pal et al. ${ }^{34}$ also demonstrated that $\mathrm{OH}^{-}$at $\mathrm{O} 5$ has no direct-H-bond partner in their $\mathrm{S}_{0}$ model; this implies that the 'energy barrier' for PT with O5 must be high. Indeed, Pal et al. demonstrated that O5 deprotonation 

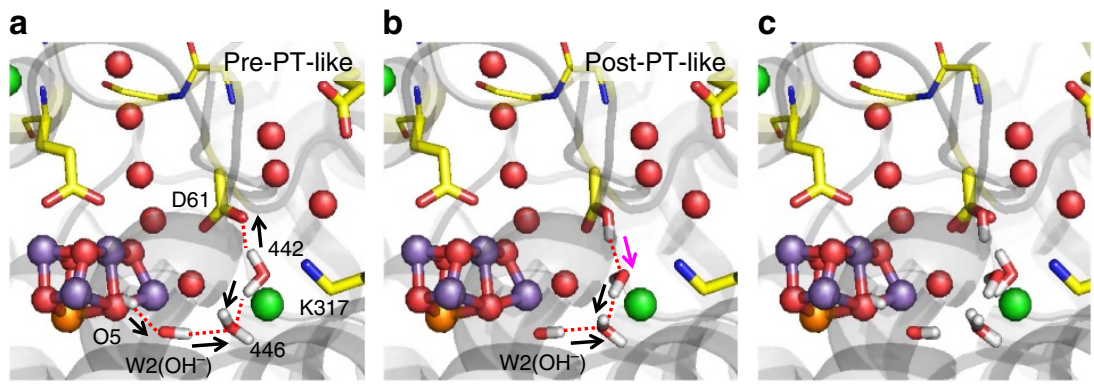

Figure 5 | QM/MM optimized geometries. (a) pre-PT-like, (b) post-PT-like and (c) both conformations. Initial donor-to-acceptor orientations are indicated by black arrows, whereas altered donor-to-acceptor orientations in the post-PT conformation are indicated by magenta arrows.

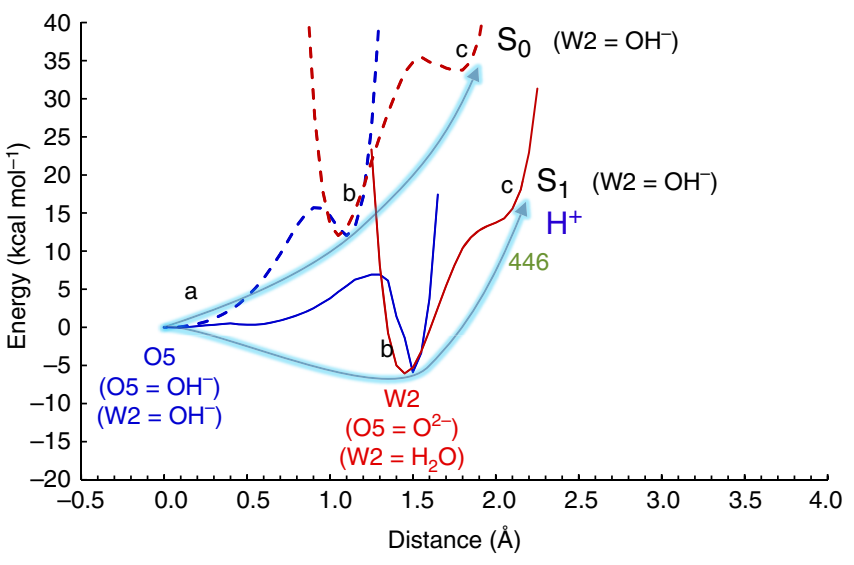

Figure 6 | The energy profiles along the PT coordinate for all of the H-bonds along the 05 path. In the pre-PT conformation; $\mathrm{S}_{1}$ (solid curves) and $\mathrm{S}_{0}$ (dotted curves) for $\mathrm{W} 2=\mathrm{OH}^{-}$(see Supplementary Fig. 6 for $\mathrm{W} 2=\mathrm{H}_{2} \mathrm{O}$ ). For comparison, the energy minimum in the $\mathrm{O} 5$ moiety was set to zero for all $\mathrm{S}$ states. Labels a-c correspond to the states in Supplementary Fig. 5a-c, respectively.

only occurred when using 'a small model of the oxidized $\mathrm{S}_{0}{ }^{\prime}$ state' (that is, not 'the QM/MM S $\mathrm{S}_{0}$ model', see supplementary Fig. $7 \mathrm{~b}$ in ref. 34), in line with our conclusions.

Siegbahn put forward a model in which $\mathrm{O} 5\left(=\mathrm{OH}^{-}\right)$ deprotonation occurred on the $\mathrm{S}_{0}-\mathrm{S}_{1}$ transition by assuming an additional water molecule near $\mathrm{O} 5$ in density functional theory (DFT) calculations ${ }^{35}$, a water molecule that is not visible not only in the original 1.9- $\AA$ structure ${ }^{14}$ but also in the recent radiationdamage-free PSII crystal structure ${ }^{36}$. This extra water molecule was positioned so that it could accept an H-bond from O5 (ref. 35). An appropriately oriented proton acceptor for O5 would significantly decrease the energy barrier for release of a proton from O5. In this case however, the actual 1.9- $\AA$ structure shows that the water molecule cannot be located at the corresponding position due to the presence of a conserved hydrophobic amino acid side-chain, D1-Val185 $\left(\mathrm{C} \gamma_{\text {Val185 }}-\mathrm{O}_{\text {water }}=\sim 2.1 \AA\right.$ in Supplementary Fig. 7). This feature is also present in the free electron laser structure, which is assumed to be in the $S_{1}$ state $^{36}$. In the O5 deprotonation model, D1-Val185 was not included in the calculation and hence was absent from the model ${ }^{35}$. Furthermore, the $\mathrm{O} 5$ deprotonation model also included a significant structural modification in the vicinity of the H-bond accepting water: the side-chain of D1-His332 was twisted (by $\sim 90^{\circ}$ ) along the $\mathrm{Mn} 1-\mathrm{N} \varepsilon_{\mathrm{His} 332}$ axis $^{35}$ compared with its position in the 1.9- $\AA$ structure. These two structural differences compared with the reference crystal structure thus allowed the water to be located close to $\mathrm{O} 5$ without the steric repulsion that
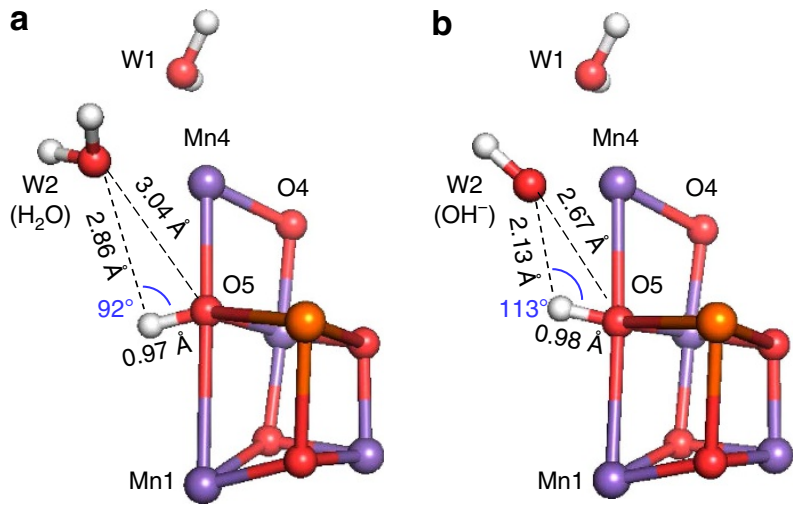

Figure 7 | H-bond patterns of the 05 and $\mathbf{W} 2$ moiety in the QM/MM geometry. (a) $\mathrm{W} 2=\mathrm{H}_{2} \mathrm{O}$ and (b) $\mathrm{W} 2=\mathrm{OH}^{-}$. For clarity, only the $\mathrm{Mn}_{4} \mathrm{CaO}_{5}$ cluster, $\mathrm{W} 1$, and $\mathrm{W} 2$ are shown.

would have occurred in the unmodified $1.9-\AA$ structure (Supplementary Fig. 7). It could be argued ad hoc that a conformational change may occur resulting in the situation modelled. However the most recent unreduced structure of the enzyme shows no sign of such changes ${ }^{36}$, so arguments for such a conformational change are not compelling. Without specific justification for the $\sim 90^{\circ}$ twist of the Mn-ligated D1-His332 side-chain and the relocation of the conserved hydrophobic D1-Val185 side-chain away from the O5 moiety, it seems unjustified to place a water molecule at the position required for it to accept an $\mathrm{H}$-bond from $\mathrm{O} 5$ for modelling the $\mathrm{S}_{0}$ and $\mathrm{S}_{1}$ transition.

The O5 deprotonation model also showed significantly large deviations of the atomic coordinates from those of the original 1.9- $\AA$ structure ${ }^{35}$ not only for D1-His 332 (root-mean-square deviation = 1.28 $\AA$ ) but also for CP43-Arg357 (1.19 $\AA)$ and D1-Glu189 (0.51 A, Supplementary Table 3). Furthermore, the $\mathrm{H}$-bond partner of O4, that is, W539, and the entire O4-water chain were also absent in the earlier mode ${ }^{35}$. These changes and omissions are expected to affect the resulting energy of the system in that model.

Overall then based on the current data, it seems clear that the deprotonation of a $\mathrm{OH}^{-}$at $\mathrm{O} 5$, as suggested earlier ${ }^{34,35}$, is less likely than deprotonation of $\mathrm{OH}^{-}$at $\mathrm{O} 4$, as suggested in the present work.

Deprotonation of the substrate oxygen and protonation of $\mathrm{O4}$. It has been proposed that the exchangeable $\mu$-oxo bridge is likely to be O5 (refs 24,29,33,52; see also relevant articles ${ }^{19,20}$ published before the detailed 1.9- $\AA$ structur ${ }^{14}$ ), and thus $\mathrm{O} 5$ is a plausible candidate for the slow exchanging substrate water molecule $\mathrm{W}_{\mathrm{s}}$ 
(ref. 53). This is not incompatible with the presence of protonated $\mathrm{O} 4$ in $\mathrm{S}_{0}$ : it is possible that the liberation of $\mathrm{O}_{2}$ on formation of $\mathrm{S}_{0}$ is associated with the release of a proton from the substrate ending up on $\mu$-oxo bridge $\mathrm{O} 4$. A similar protonation of a $\mu$-oxo bridge on liberation of $\mathrm{O}_{2}$ has been proposed in manganese catalases $^{54}$.

The O4-water chain and the low $S_{0} / S_{1}$ redox potential. The conversion of the $S_{0}$ state into the $S_{1}$ state $^{55}$ due to its oxidation by TyrD ${ }^{\bullet}$ showed that the $\mathrm{S}_{0} / \mathrm{S}_{1}$ redox potential is lower than that of TyrD redox potential ${ }^{56}$, the latter was estimated to be $\sim 720-760 \mathrm{mV}$ (refs 57,58). Given that all the $S_{0}$ present is converted to $S_{1}$ by TyrD ${ }^{\bullet}$, the $S_{0} / S_{1}$ redox potential can be taken to be $\leq 700 \mathrm{mV}$ assuming the estimates for TyrD redox couple are reasonable. In contrast, the $S_{1} / S_{2}$ and $S_{2} / S_{3}$ redox potentials are clearly higher since they oxidize $\mathrm{TyrD}^{56}$ and they have been suggested to be $\sim 900-950 \mathrm{mV}$ (ref. 58). Thus, the barrier-less deprotonation and the subsequent downhill PT reaction occurring on the $S_{0}-S_{1}$ transition may contribute to the uniquely low redox potential of this redox couple, compared with those of the other S-state transitions. As demonstrated by Warshel and coworkers $^{47,51}$, low-barrier H-bonds (including single-well $\mathrm{H}$-bonds), where the $\mathrm{p} K_{\mathrm{a}}$ difference for the donor and acceptor moieties is nearly zero (that is, less polarized), are particularly unstable in polar protein environments. An $\mathrm{O}_{4}-\mathrm{O}_{\mathrm{W} 539} \mathrm{H}$-bond will become a very unstable low-barrier $\mathrm{H}$-bond upon oxidation to $S_{1}$, resulting in the release of the proton via the O4-water chain (Table 1). This is consistent with the observation that $S_{1}$ does not spontaneously back-react to form $S_{0}$ (ref. 59). PT may proceed through different pathways depending on the S-state transitions ${ }^{5-7}$. Intriguingly, it has been reported that the rate constant for the $\mathrm{S}_{0}-\mathrm{S}_{1}$ transition is essentially $\mathrm{pH}$-independent, whereas that for $\mathrm{S}_{2}-\mathrm{S}_{3}$ transition is $\mathrm{pH}$-dependent ${ }^{21,48,49}$. Ionizable groups are more likely to be involved in a PT pathway for a $\mathrm{pH}$-dependent process than a $\mathrm{pH}$-independent process; this fits with the suggestion that the uncharged $\mathrm{O} 4$-water chain may be active in the $S_{0}-S_{1}$ transition.

Changes in Mn-Mn distances by Mn oxidation/deprotonation. On proton release from $\mathrm{O} 4$, the $\mathrm{Mn}$ ion undergoing oxidation was Mn3 (Fig. 8). We note that the Mn undergoing oxidation is unlikely to be Mn4 because it appears to be the most reduced site, that is, it has the highest potential (for example, refs 29 and 60). Our results suggest that on formation of $S_{1}$, oxidation of Mn3 from the III valence to IV favours the release of the proton from $\mathrm{OH}^{-}$at $\mathrm{O} 4$ (Fig. 8). From ENDOR, electron paramagnetic resonance (EPR) and simulation of the EXAFS, it has been proposed that a $\mathrm{Mn}-\mathrm{Mn}$ distance of $\sim 2.85 \AA$ in the $\mathrm{S}_{0}$ state is decreased to $\sim 2.7 \AA$ in the $S_{1}$ state (2.83-2.73 $\AA$ (ref. 16), 2.85$2.72 \AA$ (ref. 19) or 2.85-2.75 (ref. 20)). In the present calculations, Mn3-Mn4 was the only distance that was decreased by $\sim 0.1 \AA$ from $2.86 \AA$ in $\mathrm{S}_{0}$ to $2.70 \AA$ in $\mathrm{S}_{1}$ (Table 2 and Supplementary Table 4). Note that the corresponding change was 2.90 , a slightly longer distance, to $2.71 \AA$ when O5 was assumed to be the deprotonation site ${ }^{34}$. These results suggest that the decreased Mn-Mn distance reported in EXAFS studies ${ }^{16-21}$ corresponds to the Mn3-Mn4 distance, which is decreased by deprotonation of $\mathrm{O} 4$ in the $\mathrm{S}_{0}-\mathrm{S}_{1}$ transition.

$\mathrm{Mn3}-\mathrm{Mn} 4$ is a key distance that can allow us to evaluate the reduction state of PSII crystal structures with respect to geometries obtained from ENDOR, EPR or simulation of the EXAFS ${ }^{16-21}$ in both $S_{0}$ and $S_{1}$. The Mn3-Mn4 distance of $2.87 \AA$ in the free electron laser structure ${ }^{36}$, which was reproduced $\left(2.91 \AA\right.$ with $\mathrm{OH}^{-}$ at $\mathrm{O} 5$ in $\mathrm{S}_{1}$ ) in QM/MM studies by Shoji et al. ${ }^{61}$ is close to the distance of $\mathrm{S}_{0}(\sim 2.85 \AA)$, not the distance of $\mathrm{S}_{1}(\sim 2.73 \AA)$, obtained from ENDOR, EPR and EXAFS. This is in line with the presence of significant amount of the reduced $S_{0}$ state suggested from recent QM/MM studies by Askerka et al. ${ }^{38}$ It seems likely that the geometry of the free electron laser structure does not represent a pure $S_{1}$ state detected ENDOR, EPR and EXAFS ${ }^{16-21}$ and is probably in a more reduced state.

An argument for the presence of a hydroxide ion at $\mathrm{O} 5$ for the free electron laser structure proposed by Suga et al. ${ }^{36}$ was the observation of significantly lengthened distances between $\mathrm{O} 5$ and the adjacent $\mathrm{Mn}$ ions. The presence of a hydroxide ion at $\mathrm{O} 5$ was considered likely because recent QM/MM studies by Shoji et al. ${ }^{61}$ have reproduced two of the three significantly lengthened distances between $\mathrm{O} 5$ and the adjacent Mn ions, Mn1-O5 (2.70 $\AA$ (ref. 36) and $2.73 \AA$ (ref. 61)) and Mn4-O5 (2.33 A (ref. 36) and $2.34 \AA$ (ref. 61)), by assuming $\mathrm{OH}^{-}$at $\mathrm{O} 5$ in $\mathrm{S}_{1}$ (ref. 61). However, it should also be noted that one of the three significantly lengthened distances in the free electron laser structure, Mn3-O5, could not be reproduced in this study ${ }^{61}$; in fact Mn3-O5 was significantly shortened in the QM/MM geometry (2.20 ̊ (ref. 36) to $1.96 \AA$ (ref. 61)). Indeed, the $1.9 \AA$ structure has an even longer Mn3-O5 distance of $2.38 \AA$ (ref. 14). Notably, a similar Mn3-O5 distance of $2.37 \AA$ was obtained, assuming reduced $\mathrm{Mn}$ (II) for Mn4 in DFT studies by Petrie et al. ${ }^{62}$.

These features of the free electron laser structure, (i) the lengthened Mn3-Mn4 distance with respect to $S_{0}$ of ENDOR, EPR and EXAFS ${ }^{16-21}$ and (ii) the lengthened Mn3-O5 distance with respect to the QM/MM geometry $\left(\mathrm{S}_{1}\right.$ with $\mathrm{OH}^{-}$at $\mathrm{O} 5$ (ref. 61)), suggest that $\mathrm{Mn}_{4} \mathrm{CaO}_{5}$ of the free electron laser structure is probably reduced and cannot be simply explained as representing a single oxidation (and protonation) state.
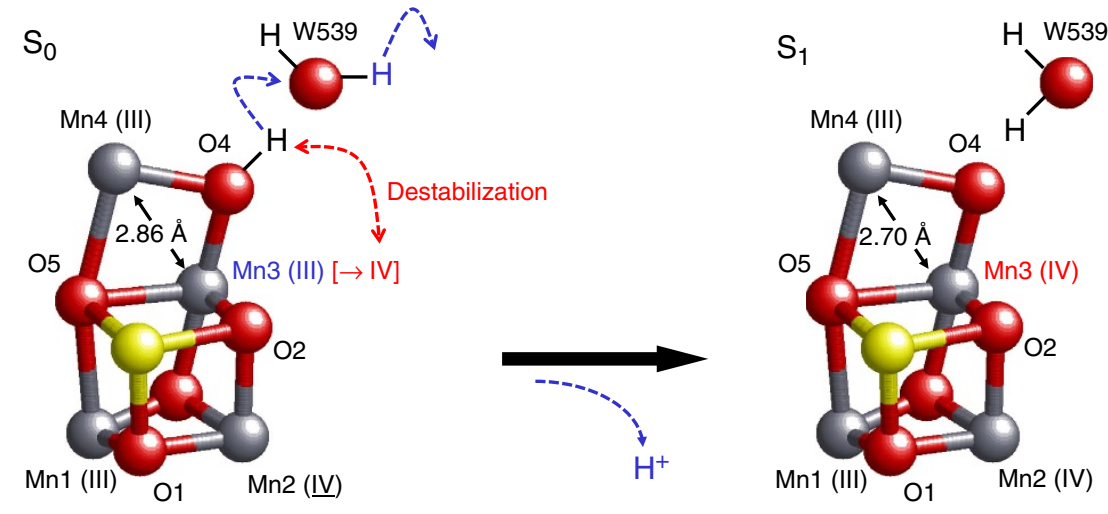

Figure 8 | Oxidation states of the four $\mathbf{M n}$ ions and protonation states of the $\mathbf{O}$ atoms. The release of a proton from $\mathrm{O} 4$ occurs due to oxidation at $\mathrm{O} 4$ via the single-well $\mathrm{H}$-bond with W539 upon formation of $\mathrm{S}_{1}$. 
Table 2 | Mn-Mn distances ( $\AA$ ).

\begin{tabular}{|c|c|c|}
\hline & $S_{0}:$ pre-PT $\left(04=\mathrm{OH}^{-}\right)$ & $S_{1}:$ post-PT $\left(04=0^{2-}\right)$ \\
\hline Mn1-4 & III, IV, IV, III & III, IV, IV, III \\
\hline Mn1-Mn2 & 2.75 & 2.75 \\
\hline Mn2-Mn3 & 2.76 & 2.76 \\
\hline Mn1-Mn3 & 3.36 & 3.28 \\
\hline Mn3-Mn4 & 2.86 & $2.70^{\star}$ \\
\hline Mn1-Mn4 & 4.74 & 4.81 \\
\hline
\end{tabular}

*Essentially consistent with the value of $2.71 \AA$ in $\mathrm{S}_{1}\left(\mathrm{O} 4\right.$ and $\mathrm{O} 5=\mathrm{O}^{2-}$ ) in other studies (for example, ref. 34).

\section{Discussion}

Based on the findings reported here, we are able to propose a mechanism for PT along the O4-water chain. (Note that the role of the O4-water chain as a proton channel as proposed here does not exclude a role as a substrate channel on other steps of the cycle.) On the $S_{0}-S_{1}$ transition deprotonation of a $\mu$-hydroxo group at the $\mathrm{O} 4$ position occurs due to oxidation of Mn3(III) to Mn3(IV) (Fig. 8). This deprotonation results in a decrease in the Mn3-Mn4 distance from 2.86 to $2.70 \AA \AA$ (Table 2 and Supplementary Table 4); a similar decrease in the Mn-Mn separation has been reported in ENDOR, EPR or EXAFS studies ${ }^{16,19,20}$. The nature of the O4water chain, being composed exclusively of water molecules, is consistent with and may explain the $\mathrm{pH}$-independence of $\mathrm{PT}$ in the $S_{0}-S_{1}$ transition $21,48,49$. At the start of the O4-water chain, the proton in the barrier-less $\mathrm{O}_{4}-\mathrm{O}_{\mathrm{W} 539} \mathrm{H}$-bond is likely to move away from the positively charged $\mathrm{S}_{1}$ when it forms. Thus, the O4$\mathrm{O}_{\mathrm{W} 539} \mathrm{H}$-bond is energetically less stable in $\mathrm{S}_{1}$, resulting in the sequential (Fig. 2) and downhill (Fig. 4) PT reaction. The presence of the O4-water chain may explain why formation of the $S_{1}$ state is less inhibited by $\mathrm{Cl}^{-}$depletion ${ }^{63}$. It may also explain the apparently irreversibility of $\mathrm{S}_{0}-\mathrm{S}_{1}$ step $^{59}$ and the redox potential of $\mathrm{S}_{0} / \mathrm{S}_{1}$ being uniquely low, lower than the TyrD redox potential ${ }^{56,58}$, resulting in the conversion of $S_{0}-S_{1}$ in the dark $k^{55,56}$.

It has been suggested that in bacteriorhodopsin, the PT occurs to the Schiff base along a chain of three water molecules, by transforming from the pre-PT to post-PT patterns ${ }^{64}$. As far as we are aware the $\mathrm{O} 4$-water chain is the longest $\mathrm{PT}$ channel of water molecules ( $\sim 8$-water molecules) identified in protein crystal structures. This unusually long and straight water chain, which seems to function as a PT pathway in the water-oxidizing enzyme, is worthy of study in its own right.

\section{Methods}

Coordinates and atomic partial charges. The atomic coordinates of PSII were taken from the X-ray structure of PSII monomer unit 'A' of the PSII complexes from Thermosynechococcus vulcanus at a resolution of $1.9 \AA$ (Protein Data Bank (PDB) code, $3 \mathrm{ARC})^{14}$. Hydrogen atoms were generated and energetically optimized with $\mathrm{CHARMM}^{65}$, whereas the positions of all non-hydrogen atoms were fixed, and all titratable groups were kept in their standard protonation states (that is, acidic groups were ionized and basic groups were protonated). For the QM/MM calculations, we added additional counter ions to neutralize the entire system. Atomic partial charges of the amino acids were adopted from the all-atom CHARMM22 (ref. 66) parameter set. The atomic charges of cofactors were taken from our previous studies of $\mathrm{PSII}^{43}$.

QM/MM calculations. We employed the electrostatic embedding QM/MM scheme, in which electrostatic and steric effects created by a protein environment were explicitly considered, and we used the Qsite ${ }^{67}$ programme code, as used in previous studies ${ }^{43}$. We employed the unrestricted DFT method with the B3LYP functional and LACVP** basis sets. To analyse $\mathrm{H}$-bond potential-energy profiles of the $\mathrm{O} 4-\mathrm{O}_{\mathrm{W} 539}$ bond, the $\mathrm{QM}$ region was defined as the $\mathrm{Mn}_{4} \mathrm{CaO}_{5}$ cluster (including the ligands), water molecules shown in Fig. 1, side-chains of D1-Asp61, D1-Asn338, D2-Asn350, and CP43-Thr335, and backbones of D1-Asp61, D1-Asn335, D1-Ala336, D2-Asn350 and CP43-Gly338, whereas other protein units and all cofactors were approximated by the MM force field. To analyse all of the $\mathrm{H}$-bonds along the $\mathrm{O} 4$-water chain (Fig. 1) in the pre-PT conformation, a slightly smaller QM region was defined as (the $\mathrm{Mn}_{4} \mathrm{CaO}_{5}$ cluster (including the ligands), water molecules shown in Fig. 1 and the side-chain of CP43-Thr335) for efficiency (small QM). The two QM regions did not essentially alter the results and conclusions. The resulting geometries were essentially identical regardless of the size of the QM region (Supplementary Tables 2 and 4). The results obtained on the basis of the large QM region were described in the main text. To analyse all of the $\mathrm{H}$-bonds along the $\mathrm{O} 5$ path (Fig. 1) in the pre-PT-like conformation, the QM region was defined as (the $\mathrm{Mn}_{4} \mathrm{CaO}_{5}$ cluster (including the ligands), water molecules of W1, W2, W3, W4, W539, W538, W446, and W442, side-chains of D1-Asp61, D1-Asn181, and D2-Lys317 and a chloride ion $\left.\left(\mathrm{Cl}^{-} 1\right)\right)$. To analyze $\mathrm{H}$ bond patterns of the O5 and W2 moiety (Fig. 7), we used the QM region same as that in ref. 68. The geometries were refined by constrained QM/MM optimization. Specifically, the coordinates of the heavy atoms in the surrounding MM region were fixed at their original X-ray coordinates, while those of the $\mathrm{H}$ atoms in the MM region were optimized using the OPLS2005 force field. All of the atomic coordinates in the QM region were fully relaxed (that is, not fixed) in the QM/MM calculation. Note that the resulting atomic coordinates of the QM region essentially did not alter upon full relaxation of the entire atoms (including heavy atoms) in the surrounding MM region ${ }^{68}$. The $\mathrm{Mn}_{4} \mathrm{CaO}_{5}$ cluster was considered to be ferromagnetically coupled; for example, the total spin $S=7$ in $S_{1}$ and the resulting Mn oxidation state $(\mathrm{Mn} 1, \mathrm{Mn} 2, \mathrm{Mn} 3, \mathrm{Mn} 4)=(\mathrm{III}, \mathrm{IV}, \mathrm{IV}, \mathrm{III})$ (see Supplementary Discussion for further details). The potential-energy profiles of $\mathrm{H}$-bonds were obtained as follows: first, we prepared the QM/MM optimized geometry without constraints and used the resulting geometry as the initial geometry. The $\mathrm{H}$ atom under investigation was then moved from the $\mathrm{H}$-bond donor atom $\left(\mathrm{O}_{\text {donor }}\right)$ towards the acceptor atom $\left(\mathrm{O}_{\text {acceptor }}\right)$ by $0.05 \AA$, after which the geometry was optimized by constraining the $\mathrm{O}_{\text {donor }}-\mathrm{H}$ and $\mathrm{H}-\mathrm{O}_{\text {acceptor }}$ distances. The energy of the resulting geometry was calculated. This procedure was repeated until the $\mathrm{H}$ atom reached the $\mathrm{O}_{\text {acceptor }}$ atom. See Supplementary Data 1 for the atomic coordinates of the QM region (that is, $\mathrm{Mn}_{4} \mathrm{CaO}_{5}$ ). As discussed later, $\mathrm{OH}^{-}$at $\mathrm{O} 5$ has no direct-H-bond in the protein environment of PSII. Thus, to analyse the PT from $\mathrm{O} 5$, we assumed $\mathrm{W} 2\left(\mathrm{O} 5 \ldots \mathrm{O}_{\mathrm{W} 2}=3.1 \AA\right.$ (ref. 14)) as the plausible proton acceptor, and analysed the energy profile by constraining the $\mathrm{H}-\mathrm{O}_{\mathrm{W} 2}$ distance. We also calculated the ${ }^{1} \mathrm{H}$ NMR chemical shift for $\mathrm{OH}^{-}$at $\mathrm{O} 5$ (see Supplementary Methods and Supplementary Discussion).

\section{References}

1. Dau, H., Zaharieva, I. \& Haumann, M. Recent developments in research on water oxidation by photosystem II. Curr. Opin. Chem. Biol. 16, 3-10 (2012).

2. Cox, N. \& Messinger, J. Reflections on substrate water and dioxygen formation Biochim. Biophys. Acta 1827, 1020-1030 (2013).

3. Schlodder, E. \& Witt, H. T. Stoichiometry of proton release from the catalytic center in photosynthetic water oxidation. J. Biol. Chem. 274, 30387-30392 (1999).

4. Suzuki, H., Sugiura, M. \& Noguchi, T. pH dependence of the flash-induced S-state transitions in the oxygen-evolving center of photosystem II from Thermosynechoccocus elongatus as revealed by Fourier transform infrared spectroscopy. Biochemistry 44, 1708-1718 (2005).

5. Haumann, M. \& Junge, W. Photosynthetic water oxidation: a simplex-scheme of its partial reactions. Biochim. Biophys. Acta 1411, 86-91 (1999).

6. Vrettos, J. S., Limburg, J. \& Brudvig, G. W. Mechanism of photosynthetic water oxidation: combining biophysical studies of photosystem II with inorganic model chemistry. Biochim. Biophys. Acta 1503, 229-245 (2001).

7. Renger, G. Photosynthetic water oxidation to molecular oxygen: apparatus and mechanism. Biochim. Biophys. Acta 1503, 210-228 (2001).

8. Murray, J. W. \& Barber, J. Structural characteristics of channels and pathways in photosystem II including the identification of an oxygen channel. J. Struct. Biol. 159, 228-237 (2007).

9. Ho, F. M. \& Styring, S. Access channels and methanol binding site to the $\mathrm{CaMn}_{4}$ cluster in photosystem II based on solvent accessibility simulations, with implications for substrate water access. Biochim. Biophys. Acta 1777, 140-153 (2008).

10. Vassiliev, S., Zaraiskaya, T. \& Bruce, D. Exploring the energetics of water permeation in photosystem II by multiple steered molecular dynamics simulations. Biochim. Biophys. Acta 1817, 1671-1678 (2012).

11. Ogata, K., Yuki, T., Hatakeyama, M., Uchida, W. \& Nakamura, S. All-atom molecular dynamics simulation of photosystem II embedded in thylakoid membrane. J. Am. Chem. Soc. 135, 15670-15673 (2013).

12. Linke, K. \& Ho, F. M. Water in photosystem II: structural, functional and mechanistic considerations. Biochim. Biophys. Acta 1837, 14-32 (2014).

13. Dilbeck, P. L., Bao, H., Neveu, C. L. \& Burnap, R. L. Perturbing the water cavity surrounding the manganese cluster by mutating the residue D1-valine 185 has a strong effect on the water oxidation mechanism of photosystem II. Biochemistry 52, 6824-6833 (2013).

14. Umena, Y., Kawakami, K., Shen, J.-R. \& Kamiya, N. Crystal structure of oxygen-evolving photosystem II at a resolution of $1.9 \AA$. Nature 473, 55-60 (2011).

15. Gatt, P., Petrie, S., Stranger, R. \& Pace, R. J. Rationalizing the $1.9 \AA$ crystal structure of photosystem II-a remarkable Jahn-Teller balancing act induced by a single proton transfer. Angew. Chem. Int. Ed. 51, 12025-12028 (2012). 
16. Baldwin, M. J. et al. Structural and magnetic effects of successive protonations of oxo bridges in high-valent manganese dimers. J. Am. Chem. Soc. 116, 11349-11356 (1994)

17. Yano, J. et al. X-ray damage to the $\mathrm{Mn}_{4} \mathrm{Ca}$ complex in single crystals of photosystem II: a case study for metalloprotein crystallography. Proc. Natl Acad. Sci. USA 102, 12047-12052 (2005).

18. Grabolle, M., Haumann, M., Muller, C., Liebisch, P. \& Dau, H. Rapid loss of structural motifs in the manganese complex of oxygenic photosynthesis by X-ray irradiation at 10-300 K. J. Biol. Chem. 281, 4580-4588 (2006).

19. Robblee, J. H. et al. The Mn cluster in the $S_{0}$ state of the oxygen-evolving complex of photosystem II studied by EXAFS spectroscopy: are there three di- $\mu$-oxo-bridged $\mathrm{Mn}_{2}$ moieties in the tetranuclear Mn complex? J. Am. Chem. Soc. 124, 7459-7471 (2002).

20. Kulik, L. V., Epel, B., Lubitz, W. \& Messinger, J. Electronic structure of the $\mathrm{Mn}_{4} \mathrm{O}_{\mathrm{x}} \mathrm{Ca}$ cluster in the $\mathrm{S}_{0}$ and $\mathrm{S}_{2}$ states of the oxygen-evolving complex of photosystem II based on pulse ${ }^{55} \mathrm{Mn}$-ENDOR and EPR spectroscopy. J. Am. Chem. Soc. 129, 13421-13435 (2007).

21. Dau, H. \& Haumann, M. The manganese complex of photosystem II in its reaction cycle? Basic framework and possible realization at the atomic level. Coord. Chem. Rev. 252, 273-295 (2008)

22. Krewald, V. et al. Metal oxidation states in biological water splitting. Chem. Sci. 6, 1676-1695 (2015).

23. Britt, R. D. et al. Recent pulsed EPR studies of the photosystem II oxygenevolving complex: implications as to water oxidation mechanisms. Biochim. Biophys. Acta 1655, 158-171 (2004).

24. Rapatskiy, L. et al. Detection of the water-binding sites of the oxygen-evolving complex of photosystem II using W-band ${ }^{17} \mathrm{O}$ electron-electron double resonance-detected NMR spectroscopy. J. Am. Chem. Soc. 134, 16619-16634 (2012).

25. Messinger, J. Evaluation of different mechanistic proposals for water oxidation in photosynthesis on the basis of $\mathrm{Mn}_{4} \mathrm{O}_{\mathrm{x}} \mathrm{Ca}$ structures for the catalytic site and spectroscopic data. Phys. Chem. Chem. Phys. 6, 4764-4771 (2004).

26. Koua, F. H., Umena, Y., Kawakami, K. \& Shen, J. R. Structure of Sr-substituted photosystem II at $2.1 \AA$ resolution and its implications in the mechanism of water oxidation. Proc. Natl Acad. Sci. USA 110, 3889-3894 (2013).

27. Hillier, W., Messinger, J. \& Wydrzynski, T. Kinetic determination of the fast exchanging substrate water molecule in the $\mathrm{S}_{3}$ state of photosystem II. Biochemistry 37, 16908-16914 (1998).

28. Kusunoki, M. $\mathrm{S}_{1}$-state $\mathrm{Mn}_{4} \mathrm{Ca}$ complex of photosystem II exists in equilibrium between the two most-stable isomeric substates: XRD and EXAFS evidence. $J$. Photochem. Photobiol. B 104, 100-110 (2011).

29. Cox, N., Pantazis, D. A., Neese, F. \& Lubitz, W. Biological water oxidation. Acc. Chem. Res. 46, 1588-1596 (2013).

30. Sproviero, E. M. et al. QM/MM computational studies of substrate water binding to the oxygen-evolving centre of photosystem II. Philos. Trans. R. Soc. Lond. B Biol. Sci. 363, 1149-1156 (2008).

31. Siegbahn, P. E. Substrate water exchange for the oxygen evolving complex in PSII in the $S_{1}, S_{2}$, and $S_{3}$ states. J. Am. Chem. Soc. 135, $9442-9449$ (2013).

32. Perez Navarro, M. et al. Ammonia binding to the oxygen-evolving complex of photosystem II identifies the solvent-exchangeable oxygen bridge ( $\mu$-oxo) of the manganese tetramer. Proc. Natl Acad. Sci. USA 110, 15561-15566 (2013).

33. McConnell, I. L. et al. EPR-ENDOR characterization of $\left({ }^{17} \mathrm{O},{ }^{1} \mathrm{H},{ }^{2} \mathrm{H}\right)$ water in manganese catalase and its relevance to the oxygen-evolving complex of photosystem II. J. Am. Chem. Soc. 134, 1504-1512 (2012).

34. Pal, R. et al. S-State model of the oxygen-evolving complex of photosystem II. Biochemistry 52, 7703-7706 (2013).

35. Siegbahn, P. E. Water oxidation mechanism in photosystem II, including oxidations, proton release pathways, $\mathrm{O}-\mathrm{O}$ bond formation and $\mathrm{O}_{2}$ release. Biochim. Biophys. Acta 1827, 1003-1019 (2013).

36. Suga, M. et al. Native structure of photosystem II at $1.95 \AA$ resolution viewed by femtosecond X-ray pulses. Nature 517, 99-103 (2015).

37. Grundmeier, A. \& Dau, H. Structural models of the manganese complex of photosystem II and mechanistic implications. Biochim. Biophys. Acta 133, 88-105 (2012)

38. Askerka, M., Vinyard, D. J., Wang, J., Brudvig, G. W. \& Batista, V. S. Analysis of the radiation-damage-free X-ray structure of photosystem II in light of EXAFS and QM/MM data. Biochemistry 54, 1713-1716 (2015).

39. Mikenda, W. Stretching frequency versus bond distance correlation of $\mathrm{O}-\mathrm{D}(\mathrm{H}) \ldots \mathrm{Y}(\mathrm{Y}=\mathrm{N}, \mathrm{O}, \mathrm{S}, \mathrm{Se}, \mathrm{Cl}, \mathrm{Br}, \mathrm{I})$ hydrogen bonds in solid hydrates. J. Mol. Struct. 147, 1-15 (1986).

40. Limbach, H.-H. et al. OHO hydrogen bond geometries and NMR chemical shifts: from equilibrium structures to geometric H/D isotope effects, with applications for water, protonated water, and compressed ice. Isr. J. Chem. 49, 199-216 (2009)

41. Jeffrey, G. A. An Introduction To Hydrogen Bonding (Oxford University Press, 1997)

42. Frey, P. A. in Isotope Effects In Chemistry And Biology (eds Kohen, A. \& Limbach, H.-H.) 975-993 (CRC press, 2006).
43. Saito, K., Shen, J.-R., Ishida, T. \& Ishikita, H. Short hydrogen-bond between redox-active tyrosine $\mathrm{Y}_{\mathrm{Z}}$ and D1-His190 in the photosystem II crystal structure. Biochemistry 50, 9836-9844 (2011)

44. Saito, K., Rutherford, A. W. \& Ishikita, H. Mechanism of proton-coupled quinone reduction in photosystem II. Proc. Natl Acad. Sci. USA 110, 954-959 (2013).

45. Ishikita, H. \& Saito, K. Proton transfer reactions and hydrogen-bond networks in protein environments. J. R. Soc. Interface 11, 20130518 (2014).

46. Guskov, A. et al. Cyanobacterial photosystem II at 2.9-Å resolution and the role of quinones, lipids, channels and chloride. Nat. Struct. Mol. Biol. 16, 334-342 (2009).

47. Warshel, A., Papazyan, A. \& Kollman, P. A. On low-barrier hydrogen bonds and enzyme catalysis. Science 269, 102-106 (1995).

48. Renger, G. \& Hanssum, B. Studies on the reaction coordinates of the water oxidase in PS II membrane fragments from spinach. FEBS Lett. 299, 28-32 (1992).

49. Haumann, M., Bögershausen, O., Cherepanov, D., Ahlbrink, R. \& Junge, W. Photosynthetic oxygen evolution: H/D isotope effects and the coupling between electron and proton transfer during the redox reactions at the oxidizing side of photosystem II. Photosynth. Res. 193, 193-208 (1997).

50. Stuchebrukhov, A. A. Mechanisms of proton transfer in proteins: localized charge transfer versus delocalized soliton transfer. Phys. Rev. E Stat. Nonlin. Soft Matter Phys. 79, 031927 (2009).

51. Schutz, C. N. \& Warshel, A. The low barrier hydrogen bond (LBHB) proposal revisited: the case of the Asp... His pair in serine proteases. Proteins 55, 711-723 (2004).

52. Galstyan, A., Robertazzi, A. \& Knapp, E. W. Oxygen-evolving Mn cluster in photosystem II: the protonation pattern and oxidation state in the high-resolution crystal structure. J. Am. Chem. Soc. 134, 7442-7449 (2012).

53. Hillier, W. \& Wydrzynski, T. The affinities for the two substrate water binding sites in the $\mathrm{O}_{2}$ evolving complex of photosystem II vary independently during S-state turnover. Biochemistry 39, 4399-4405 (2000).

54. Whittaker, M. M., Barynin, V. V., Antonyuk, S. V. \& Whittaker, J. W. The oxidized $(3,3)$ state of manganese catalase. Comparison of enzymes from Thermus thermophilus and Lactobacillus plantarum. Biochemistry 38, 9126-9136 (1999).

55. Vermaas, W. F. J., Renger, G. \& Dohnt, G. The reduction of the oxygenevolving system in chloroplasts by thylakoid components. Biochim. Biophys. Acta 764, 194-202 (1984).

56. Styring, S. \& Rutherford, A. W. In the oxygen-evolving complex of photosystem II the $\mathrm{S}_{0}$ state is oxidized to the $\mathrm{S}_{1}$ state by $\mathrm{D}^{+}$(signal $\mathrm{II}_{\text {slow }}$ ). Biochemistry 26, 2401-2405 (1987).

57. Boussac, A. \& Etienne, A. L. Midpoint potential of signal II (slow) in Tris-washed photosystem-II particles. Biochim. Biophys. Acta 766, 576-581 (1984).

58. Vass, I. \& Styring, S. pH-dependent charge equilibria between tyrosine-D and the $\mathrm{S}$ states in photosystem II. Estimation of relative midpoint redox potentials. Biochemistry 30, 830-839 (1991).

59. Kok, B., Forbush, B. \& McGloin, M. Cooperation of charges in photosynthetic $\mathrm{O}_{2}$ evolution-I. A linear four step mechanism. Photochem. Photobiol. 11, 457-475 (1970).

60. Kurashige, Y., Chan, G. K. \& Yanai, T. Entangled quantum electronic wavefunctions of the $\mathrm{Mn}_{4} \mathrm{CaO}_{5}$ cluster in photosystem II. Nat. Chem. 5, 660-666 (2013).

61. Shoji, M. et al. Theoretical studies of the damage-free $S_{1}$ structure of the $\mathrm{CaMn}_{4} \mathrm{O}_{5}$ cluster in oxygen-evolving complex of photosystem II. Chem. Phys. Lett. 623, 1-7 (2015)

62. Petrie, S., Pace, R. J. \& Stranger, R. Resolving the differences between the $1.9 \AA$ and $1.95 \AA$ crystal structures of photosystem II: a single proton relocation defines two tautomeric forms of the water-oxidizing complex. Angew. Chem. Int. Ed. 54, 7120-7124 (2015).

63. Wincencjusz, H., van Gorkom, H. J. \& Yocum, C. F. The photosynthetic oxygen evolving complex requires chloride for its redox state $S_{2} \rightarrow S_{3}$ and $\mathrm{S}_{3} \rightarrow \mathrm{S}_{0}$ transitions but not for $\mathrm{S}_{0} \rightarrow \mathrm{S}_{1}$ or $\mathrm{S}_{1} \rightarrow \mathrm{S}_{2}$ transitions. Biochemistry 36, 3663-3670 (1997).

64. Freier, E., Wolf, S. \& Gerwert, K. Proton transfer via a transient linear water-molecule chain in a membrane protein. Proc. Natl Acad. Sci. USA 108, 11435-11439 (2011).

65. Brooks, B. R. et al. CHARMM: a program for macromolecular energy minimization and dynamics calculations. J. Comput. Chem. 4, 187-217 (1983).

66. MacKerell, Jr A. D. et al. All-atom empirical potential for molecular modeling and dynamics studies of proteins. J. Phys. Chem. B 102, 3586-3616 (1998).

67. QSite, version 5 8, Schrödinger, LLC, New York, NY, 2012.

68. Saito, K. \& Ishikita, H. Influence of the $\mathrm{Ca}^{2+}$ ion on the $\mathrm{Mn}_{4} \mathrm{Ca}$ conformation and the H-bond network arrangement in photosystem II. Biochim. Biophys. Acta 1837, 159-166 (2014). 
69. Bathelt, C. M., Mulholland, A. J. \& Harvey, J. N. QM/MM studies of the electronic structure of the compound I intermediate in cytochrome c peroxidase and ascorbate peroxidase. Dalton Trans. 3470-3476 (2005).

70. Wang, B. \& Truhlar, D. G. Screened electrostatic interactions in molecular mechanics. J. Chem. Theory Comput. 10, 4480-4487 (2014).

\section{Acknowledgements}

This research was supported by the JST PRESTO programme (K.S.), JSPS KAKENHI (22740276 and 26800224 to K.S. and 15H00864, 25107517, 26105012 and 26711008 to H.I.), Tokyo Ohka Foundation for The Promotion of Science and Technology (H.I.), and Biotechnological and Biological Sciences Research Council Grant (BB/K002627/1 to A.W.R.). A.W.R. is the recipient of a Wolfson Merit Award of the Royal Society.

\section{Author contributions}

H.I. designed research; K.S. and H.I. performed research; K.S., A.W.R. and H.I. analysed data; and A.W.R. and H.I. wrote the paper.

\section{Additional information}

Supplementary Information accompanies this paper at http://www.nature.com/ naturecommunications

Competing financial interests: The authors declare no competing financial interests.

Reprints and permission information is available online at http://npg.nature.com/ reprintsandpermissions/

How to cite this article: Saito, K. et al., Energetics of proton release on the first oxidation step in the water-oxidizing enzyme. Nat. Commun. 6:8488 doi: 10.1038/ncomms 9488 (2015).

(c) (i)

This work is licensed under a Creative Commons Attribution 4.0 International License. The images or other third party material in this article are included in the article's Creative Commons license, unless indicated otherwise in the credit line; if the material is not included under the Creative Commons license, users will need to obtain permission from the license holder to reproduce the material. To view a copy of this license, visit http://creativecommons.org/licenses/by/4.0/ 